\title{
Optimization of algal methyl esters using RSM and evaluation of biodiesel storage characteristics
}

\author{
Annam Renita $\mathrm{A}^{1^{*}}$, Nurshaun Sreedhar ${ }^{1}$ and Magesh Peter $\mathrm{D}^{2}$
}

\begin{abstract}
Background: This paper deals with the production of biodiesel from the brown seaweed Sargassum myriocystum, a third-generation biodiesel from the Gulf of Mannar, Rameshwaram, India. The optimization of reaction parameters was done using Design-Expert software version 8.0.7.1. Algal oil was transesterified using methanol and sodium hydroxide. The effect of oil:alcohol ratio, catalyst amount, temperature, and time on biodiesel yield was investigated by response surface methodology using central composite design.

Results: It was found that the maximum biodiesel yield was obtained at $60^{\circ} \mathrm{C}$ for 1:6 $(\mathrm{V} / \mathrm{V})$ oil:alcohol ratio, $0.4(\mathrm{~W} / \mathrm{W})$ catalyst amount, and $120 \mathrm{~min}$. The $R^{2}$, adjusted $R^{2}$, and predicted $R^{2}$ values are $0.9977,0.9956$, and 0.9923 , respectively, which implies that experimental values are in good agreement with predicted values. The fatty acid profile of $S$. myriocystum biodiesel was determined using gas chromatography. Algal biodiesel was stored in dark and light conditions. Fuel properties like kinematic viscosity and acid value were determined. It was found that the samples exposed to light led to an increase in kinematic viscosity and acid value with some sediment formation.
\end{abstract}

Conclusions: The acid value and kinematic viscosity of the samples stored in the dark environment had only marginal increase in fuel properties which were within the range specified by the American Society of Testing Materials (ASTM D6751).

Keywords: Brown seaweed; Transesterification; Biodiesel; Optimization; RSM; Fatty acid profile; Storage properties

\section{Background}

India consumes almost five times more diesel fuel than gasoline and burns about 450 million barrels a year of diesel [1]. So in India, search for alternatives is an important criterion to meet current and future energy requirements. India's tropical climate is ideal for the growth of algal species which serves as an advantage over other countries. Approximately 841 species of marine algae are found in both intertidal and deep water regions of the Indian coast [2]. Less than 100 species have been explored for biodiesel extraction. There are two global biorenewable liquid transportation fuels that might replace gasoline and diesel fuel in the future. These are bioethanol and biodiesel [3]. Biodiesel is a processed fuel derived from the esterification and transesterification of free fatty acids and triglycerides, respectively, that occur naturally in renewable biological sources such as plant oils and animal fats

\footnotetext{
* Correspondence: reniriana@gmail.com

'Department of Chemical Engineering, Sathyabama University, Jeppiaar Nagar, Rajiv Gandhi Salai, Chennai TN 119, India

Full list of author information is available at the end of the article
}

[4]. Different countries use the oil which is abundant in that particular country. India, being a peninsula, has a rich source of seaweeds. Algae are classified as microalgae and macroalgae. The potential value of microalgal fuel production is widely recognized [5-11]. Macroalgae, which are also known as seaweeds, have comparatively low lipid content. Nevertheless, they are a potential raw material for biofuel production. Biodiesel has good biodegradability, and it is expected to degrade over $98 \%$ biologically within 3 weeks while commercial diesel will only degrade $50 \%$ biologically within the same period [12]. In Indian waters, species of Sargassum are the most abundant algae [13]. The seaweeds detach themselves from the rocky substrates and are frequently washed ashore. Though details of the phytoprofile [2], antioxidant activity, free scavenger property [14], and fatty acid profile of Sargassum have been reported, optimization of biodiesel yield and storage properties have not been reported regarding its suitability as a raw material for biodiesel. Hence, this paper deals with the production of biodiesel from the brown seaweed Sargassum myriocystum as a potential resource for biodiesel. 
Algal oil extracted from the brown seaweed S. myriocystum was transesterified to biodiesel. Analysis of the biodiesel sample was done using gas chromatography-mass spectrometry (GC-MS). The GC-MS of the biodiesel sample indicated the presence of low amounts of unsaturated fatty acids [15]. Since the fatty acid profile predicted low concentration of unsaturated fatty acids, the biodiesel sample was tested for storage properties. Biodiesel production from algae is hindered by its production cost. This can be overcome by optimizing the reaction parameters to achieve maximum production of biodiesel with minimum cost of raw materials. For this research work, optimization of reaction conditions was done by Design-Expert software version 8.0.7.1 (Stat-Ease Inc., Minneapolis, MN, USA). Central composite design (CCD) was applied to optimize the catalyzed transesterification reaction variables like oil:alcohol ratio, catalyst amount, time, and temperature. Regression analysis and analysis of variance (ANOVA) tested the significance of the model. S. myriocystum is also rich in proteins and sugars. It is being used in food and pharmaceutical industries [16]. By applying the biorefinery concept, all valuable end products can be extracted from S. myriocystum, thus making the cost of algal biodiesel economically viable. This study will enable the seaweed to be considered as a potential option as a biorefinery crude.

\section{Methods}

\section{Raw materials}

The brown seaweed S. myriocystum belonging to the class Phaeophyceae was obtained from the Gulf of Mannar, Rameshwaram, India. The seaweed species was chosen because of its availability and lipid profile. It is available all through the year and shows high productivity during the months of July and September. The samples were first washed with seawater and the debris was removed manually. Then they were washed with distilled water, shade dried under the sun, and finally dried in an oven at $60^{\circ} \mathrm{C}$. Ten kilograms of wet algae was collected, and after drying, $8.8 \mathrm{~kg}$ of dry algae was obtained. Hexane $(\geq 85 \%)$, chloroform ( $\geq 98 \%$ ), methanol $(\geq 99 \%)$, and sodium hydroxide $(\geq 98 \%)$ used for the experiments were of analytical grade.

\section{Experimental method}

The dried algae, which were chopped into fine pieces, were ground into fine powder which passes through 200 mesh size. Two solvent extraction systems were tested to find out the best suitable solvent for extraction of lipids. In one system, the solvent system was hexane and the second solvent system was chloroform:methanol $(2: 1 v / v)$. The solvent extraction was done by a Soxhlet apparatus, and the extracted algal oil was vacuum evaporated in a rotary evaporator to obtain pure algal oil. The chloroform:methanol solvent system extracted lipids better than hexane. Using the chloroform:methanol solvent system, $5.2 \mathrm{~kg}$ of algal oil was extracted. The viscosity of the algal oil has to be reduced in order to be an acceptable fuel for running an engine. The most possible method of reducing the viscosity and the commercially accepted method is the chemical transesterification method. In this process, the pure algal oil was reacted with methanol in the presence of sodium hydroxide catalyst to produce fatty acid methyl esters (FAME), which more closely resemble petroleum-based diesel fuel, and glycerol is obtained as a co-product. Sodium hydroxide was dissolved in methanol and stirred for 20 min prior to transesterification to ensure the complete dissolution of sodium hydroxide pellets. Algal oil and premixed mixture of catalyst and alcohol are kept in a round-bottom flask fitted with a reflux condenser to maintain isothermal operation. The round-bottom flask was mounted on top of a magnetic stirrer, and the reaction was carried out with continuous stirring. Experiments were done with different feed ratios of oil:alcohol, catalyst amounts, temperatures, and times to obtain the highest yield of biodiesel. Experiments on volume basis for oil:alcohol ratio were done on trial and error analysis. The volume ratio was chosen for ease of application in commercial processes. All the experiments were done in triplicate to ensure the reproducibility of the data. The error of analysis for the experimental procedure is approximately $\pm 5 \%$. The product mixture is biodiesel and glycerol. Both phases were separated using a gravity separator. The biodiesel which was obtained as the upper layer was washed with hot water and cold water alternately to remove impurities like sodium hydroxide, methanol, and foam. The sample was fan dried and stored for analysis. The yield of biodiesel is estimated from Equation 1:

$$
\begin{aligned}
\text { Yield of biodiesel }= & \text { Weight of algal oil } / \text { Weight of } \\
& \text { raw material } \times 100
\end{aligned}
$$

\section{Statistical analysis}

Design-Expert software version 8.0.7.1 was used for the optimization of reaction parameters. CCD of response surface methodology (RSM) was used to optimize the parameters affecting the transesterification so as to achieve maximum yield of biodiesel. RSM can be used to find the relationship among process variables and response in an efficient manner using minimum number of experiments [17]. Several parameters affect transesterification: catalyst concentration, methanol concentration, temperature, reaction time, pressure, and type of oil [18]. The process of transesterification is affected by various factors: free fatty acids, moisture, catalyst type, catalyst concentration, molar ratio of alcohol to oil, type of alcohol, reaction time, reaction temperature, mixing 
Table 1 Coded levels for variables used in the experimental design

\begin{tabular}{lcccc}
\hline Factors & Symbol & \multicolumn{3}{c}{ Coded levels } \\
& & $\mathbf{- 1}$ & $\mathbf{0}$ & $\mathbf{+ 1}$ \\
\hline Oil:alcohol ratio $(\mathrm{V} / \mathrm{V})$ & $\mathrm{A}$ & 4 & 6 & 8 \\
Catalyst amount $(\mathrm{W} / \mathrm{W})$ & $\mathrm{B}$ & 0.1 & 0.3 & 0.5 \\
Time $(\mathrm{min})$ & $\mathrm{C}$ & 30 & 90 & 150 \\
Temperature $\left({ }^{\circ} \mathrm{C}\right)$ & $\mathrm{D}$ & 50 & 70 & 90 \\
\hline
\end{tabular}

intensity, and organic solvents [19]. The CCD of the RSM was employed to evaluate the effect of reaction time, reaction temperature, catalyst amount, and oil:alcohol ratio on biodiesel yield. The coded values for the variables are shown in Table 1.
The empirical formula to find the optimal biodiesel yield is given by Equation 2:

$$
\begin{aligned}
Y= & \beta_{0}+\beta_{1} \mathrm{~A}+\beta_{2} \mathrm{~B}+\beta_{3} \mathrm{C}+\beta_{4} \mathrm{D}+\beta_{5} \mathrm{AB}+\beta_{6} \mathrm{AC} \\
& +\beta_{7} \mathrm{AD}+\beta_{8} \mathrm{BC}+\beta_{9} \mathrm{BD}+\beta_{10} \mathrm{CD}+\beta_{11} \mathrm{~A}^{2}+\beta_{12} \mathrm{~B}^{2} \\
& +\beta_{13} \mathrm{C}^{2}+\beta_{14} \mathrm{D}^{2}
\end{aligned}
$$

where $Y$ is the measured response in percentage yield (biodiesel yield). A, B, C, and D are the coded independent inputs. $\beta_{0}$ is the intercept term and $\beta_{1}, \beta_{2}, \beta_{3}$, and $\beta_{4}$ are the coefficients showing the linear effects. $\beta_{5}, \beta_{6}, \beta_{7}$, $\beta_{8}, \beta_{9}$, and $\beta_{10}$ are the cross-product coefficients showing the interaction effects. $\beta_{11}, \beta_{12}, \beta_{13}$, and $\beta_{14}$ are the

\begin{tabular}{|c|c|c|c|c|c|c|}
\hline Run number & Oil:alcohol ratio (A) & Catalyst amount (B) & Time (C) & Temperature (D) & Experimental yield (\%) & Predicted yield (\%) \\
\hline 1 & 4 & 0.50 & 150 & 50 & 78.4 & 79.54 \\
\hline 2 & 4 & 0.10 & 30 & 90 & 59.35 & 54.09 \\
\hline 3 & 4 & 0.30 & 90 & 90 & 68.57 & 69.18 \\
\hline 4 & 6 & 0.30 & 90 & 60 & 82.11 & 83.54 \\
\hline 5 & 4 & 0.10 & 150 & 50 & 72.11 & 73.05 \\
\hline 6 & 8 & 0.50 & 30 & 90 & 73.23 & 71.79 \\
\hline 7 & 6 & 0.50 & 90 & 70 & 81.75 & 82.88 \\
\hline 8 & 4 & 0.50 & 30 & 90 & 61.62 & 60.48 \\
\hline 9 & 8 & 0.10 & 150 & 50 & 62.54 & 64.8 \\
\hline 10 & 6 & 0.30 & 90 & 60 & 82.11 & 83.54 \\
\hline 11 & 6 & 0.30 & 90 & 70 & 81.71 & 82.88 \\
\hline 12 & 8 & 0.50 & 150 & 50 & 65.70 & 69.54 \\
\hline 13 & 8 & 0.50 & 30 & 50 & 63.53 & 64.8 \\
\hline 14 & 4 & 0.10 & 150 & 90 & 71.47 & 68.88 \\
\hline 15 & 8 & 0.10 & 30 & 50 & 55.28 & 54.09 \\
\hline 16 & 8 & 0.50 & 150 & 90 & 69.85 & 71.79 \\
\hline 17 & 6 & 0.30 & 90 & 50 & 78.85 & 69.54 \\
\hline 18 & 4 & 0.10 & 30 & 50 & 55.32 & 57.7 \\
\hline 19 & 6 & 0.30 & 90 & 90 & 81.45 & 82.88 \\
\hline 20 & 6 & 0.30 & 90 & 70 & 82.11 & 83.54 \\
\hline 21 & 8 & 0.30 & 90 & 70 & 81.65 & 80.22 \\
\hline 22 & 6 & 0.30 & 30 & 70 & 69.82 & 75.52 \\
\hline 23 & 6 & 0.30 & 90 & 60 & 83.54 & 80.88 \\
\hline 24 & 8 & 0.10 & 30 & 90 & 63.95 & 69.73 \\
\hline 25 & 6 & 0.30 & 90 & 70 & 82.82 & 83.1 \\
\hline 26 & 4 & 0.50 & 150 & 90 & 67.57 & 65.25 \\
\hline 27 & 8 & 0.10 & 150 & 90 & 66.59 & 69.87 \\
\hline 28 & 6 & 0.30 & 150 & 60 & 78.23 & 82.14 \\
\hline 29 & 4 & 0.50 & 30 & 50 & 58.25 & 52.57 \\
\hline 30 & 6 & 0.10 & 90 & 70 & 49.27 & 52.88 \\
\hline
\end{tabular}
quadratic coefficients showing the squared effects.

Table 2 Central composite design matrix for Sargassum myriocystum biodiesel 


\section{Evaluation of storage properties}

A good fuel should have low amounts of unsaturated fatty acids. The fatty acid profile was determined by GC-MS. Since S. myriocystum biodiesel has low amounts of unsaturated fatty acids, the fuel was investigated for its storage properties. Fuel properties like kinematic viscosity and acid value were determined at different time intervals to determine the shelf life of $S$. myriocystum biodiesel. The samples were stored for a period of 5 months from March to July, which is the average summer period in India. The samples were stored in two different conditions. Two liters of sample was kept in a stoppered amber glass bottle and exposed to sunlight for a period of 5 months, and properties like kinematic viscosity and acid value were determined in an interval of 1 month. Another 21 of sample was kept in a stoppered amber glass bottle in a dark room for a period of 5 months, and properties like kinematic viscosity and acid value were determined at an interval of 1 month.

\section{Results and discussion}

\section{Response surface methodology}

The Design-Expert software developed a $2^{4}$ factorial CCD resulting in 30 runs with eight axial points and six replicates. The second-order polynomial equation predicted by the model for maximum algal biodiesel is given by Equation 3:

$$
\begin{aligned}
\text { Percentage yield }= & 92.88+0.52 \mathrm{~A}+1.33 \mathrm{~B}+3.43 \mathrm{C} \\
& +1.96 \mathrm{D}+1.61 \mathrm{AB}-2.22 \mathrm{AC} \\
& +1.30 \mathrm{AD}-1.45 \mathrm{BC}+0.025 \mathrm{BD} \\
& -1.21 \mathrm{CD}-3.19 \mathrm{~A}^{2}-2.94 \mathrm{~B}^{2}-8.94 \mathrm{C}^{2} \\
& -3.24 \mathrm{D}^{2}
\end{aligned}
$$

where A, B, C, D are the coded forms of oil:alcohol ratio, catalyst amount, time, and temperature, respectively. $\mathrm{AB}, \mathrm{AC}, \mathrm{AD}, \mathrm{BC}, \mathrm{BD}$, and $\mathrm{CD}$ are the interaction terms, and $A^{2}, B^{2}, C^{2}$, and $D^{2}$ are the squared terms of the independent variables. The CCD matrix is represented by Table 2. Table 3 shows ANOVA.

The results of ANOVA for the predicted values fit well with the experimental values. The goodness of fit of the model is predicted by the determination coefficient value of 0.9977 and the adjusted $R^{2}$ values of 0.9956 . The predicted value is also in good agreement with adjusted $R^{2}$ value implying the significance of the model. Only $0.23 \%$ of the sample variance could not be satisfactorily ex-

\begin{tabular}{|c|c|c|c|c|c|c|}
\hline Source & $\begin{array}{l}\text { Sum of } \\
\text { squares }\end{array}$ & $d f$ & $\begin{array}{c}\text { Mean } \\
\text { square }\end{array}$ & $\begin{array}{c}F \\
\text { value }\end{array}$ & $\begin{array}{c}p \text { value } \\
\text { probability }>F\end{array}$ & \\
\hline Model & $2,480.56$ & 14 & 177.18 & 465.69 & $<0.0001$ & Significant \\
\hline A & 4.80 & 1 & 4.80 & 12.63 & 0.0029 & \\
\hline B & 32.00 & 1 & 32.00 & 84.10 & $<0.0001$ & \\
\hline C & 212.18 & 1 & 212.18 & 557.67 & $<0.0001$ & \\
\hline D & 68.84 & 1 & 68.84 & 180.92 & $<0.0001$ & \\
\hline$A B$ & 41.60 & 1 & 41.60 & 109.34 & $<0.0001$ & \\
\hline$A C$ & 79.21 & 1 & 79.21 & 208.19 & $<0.0001$ & \\
\hline$A D$ & 27.04 & 1 & 27.04 & 71.07 & $<0.0001$ & \\
\hline$B C$ & 33.64 & 1 & 33.64 & 88.42 & $<0.0001$ & \\
\hline $\mathrm{BD}$ & & 1 & & 0.026 & 0.8734 & \\
\hline$C D$ & 23.52 & 1 & 23.52 & 61.82 & $<0.0001$ & \\
\hline$A^{2}$ & 36.28 & 1 & 36.28 & 69.08 & $<0.0001$ & \\
\hline$B^{2}$ & 23.32 & 1 & 23.32 & 58.66 & $<0.0001$ & \\
\hline$C^{2}$ & 206.85 & 1 & 206.85 & 543.65 & $<0.0001$ & \\
\hline$D^{2}$ & 27.12 & 1 & 27.12 & 71.27 & $<0.0001$ & \\
\hline Residual & 5.71 & 15 & 0.38 & & & \\
\hline Lack of fit & 3.37 & 10 & 0.34 & 0.72 & 0.6909 & $\begin{array}{c}\text { Not } \\
\text { significant }\end{array}$ \\
\hline Pure error & 2.33 & 5 & 0.47 & & & \\
\hline $\begin{array}{l}\text { Correlated } \\
\text { total }\end{array}$ & $2,486.27$ & 29 & & & & \\
\hline
\end{tabular}
plained by the model. Hence, the predictability of the model is at $99 \%$ confidence interval. Lack of fit is also not significant, indicating the goodness of fit of the model. The $p$ value serves as a tool to check the significance of each coefficient. The smaller the $p$ value and the larger the $F$ value, the more significant is the parameter reflecting the relative importance of the term attached to that parameter [20]. ANOVA for the response surface quadratic model gave an $F$ value of 465.69 , with a $p$ value of $<0.0001$, implying its significance.

Two-dimensional (contour) and three-dimensional (surface) plots indicate the effect of interaction of the different test variables on the predicted response. The threedimensional graphs and contour graphs are the common graphical representation of the regression equation which shows the optimal values of each dependent variable [21]. Four surface and contour plots are shown to indicate the effect of interaction of oil:alcohol ratio, catalyst amount, time, and temperature on biodiesel yield. From the shape of contour plots, one could estimate the significance of the mutual interactions between the independent variables in that an elliptical profile of the contour plots indicates a remarkable interaction between the independent variables [22]. Figures $1 \mathrm{a}$ and $2 \mathrm{a}$ show the interaction between temperature and time on biodiesel yield. They show the interaction between time and temperature at a catalyst amount of 0.4 $(w / w)$ and oil:alcohol ratio of 1:6 $(v / v)$. The midpoint of the plots gives the maximum value of $81.79 \%$ which is obtained at 1:6 $(v / v)$ oil:alcohol ratio 

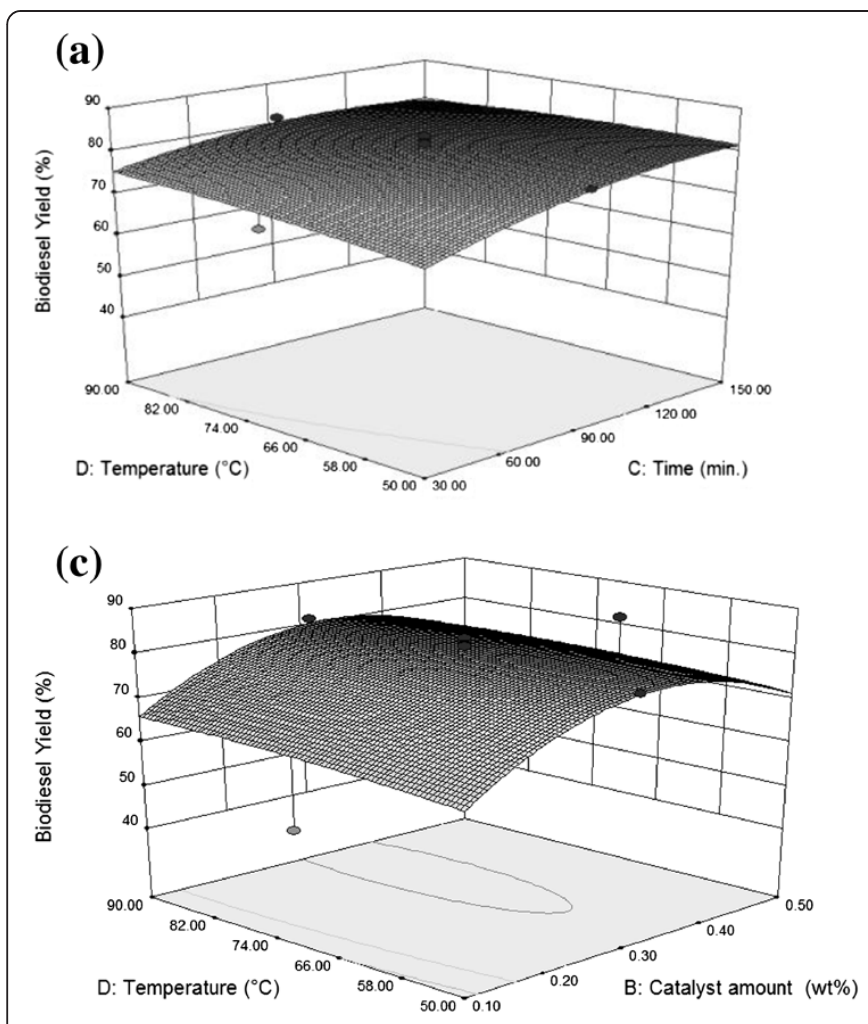

(b)

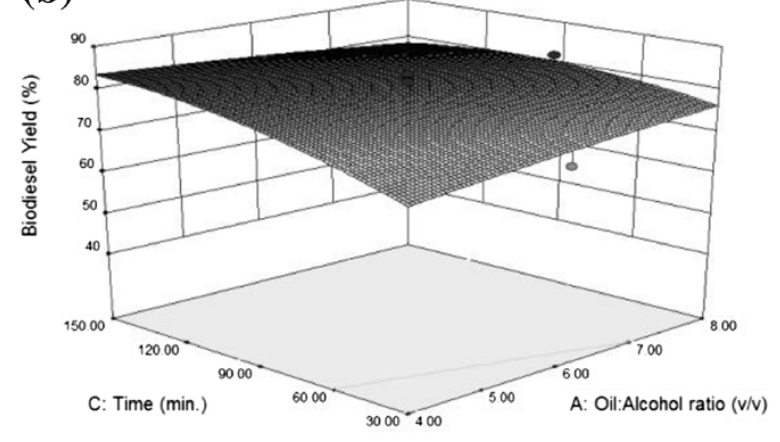

(d)

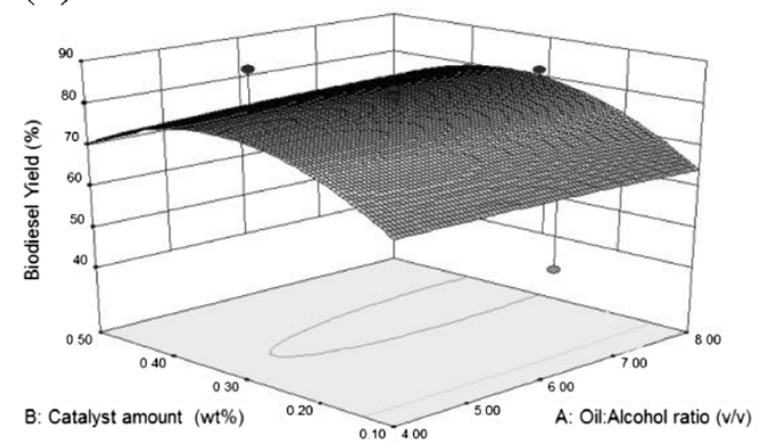

Figure 1 Response surface plots for percentage yield (\%) of Sargassum myriocystum biodiesel. (a) Temperature (D) vs time (C). (b) Time (C) vs oil:alcohol ratio (A). (c) Temperature (D) vs catalyst amount (B). (d) Catalyst amount (B) vs. oil:alcohol ratio (A).

and $120 \mathrm{~min}$. For low oil:alcohol ratio, the yield value is marginally low at $49.18 \%$. High oil:alcohol ratios are not economically and environmentally viable. Moreover, excessive methanol amounts may reduce the concentration of the catalyst in the reactant mixture and retard the transesterification reaction [23]. Figures $1 \mathrm{~b}$ and $2 \mathrm{~b}$ show the interaction between time and oil:alcohol ratio on biodiesel yield. The biodiesel yield progressively increases as temperature increases and shows a decline after $60^{\circ} \mathrm{C}$. This could be due to the fact that the solvent tends to evaporate after $60^{\circ} \mathrm{C}$ since it exceeds its boiling point. Figures $1 \mathrm{c}$ and $2 \mathrm{c}$ show the interaction between temperature and catalyst amount on biodiesel yield. At low catalyst concentration, the biodiesel yield shows a decline till $0.3 \mathrm{wt} \%$ and starts increasing from 0.4 to $0.5 \mathrm{wt} \%$. After $0.4 \mathrm{wt} \%$, the washing of the biodiesel layer developed more foam because of the residual catalyst. Figures $1 \mathrm{~d}$ and $2 \mathrm{~d}$ show the interaction between catalyst amount and oil: alcohol ratio on biodiesel yield. The biodiesel yield progressively increases as oilalcohol ratio increases and starts decreasing after 1:7. At low oil:alcohol ratio, phase separation between biodiesel and glycerol layer was not observed, and as the ratio increased, a good phase separation was achieved.

The optimum values of the variables as predicted by the model are 1:6 $(v / v)$ oil:alcohol ratio, $0.4(w / w)$ catalyst amount, $120 \mathrm{~min}$, and $60^{\circ} \mathrm{C}$. Experiments were carried out to validate the optimum conditions indicated by the model. The experimental result obtained was $79.5 \%$ biodiesel yield with a $3.6 \%$ error to the value of $83.54 \%$ predicted by the model. The experiment was done in triplicate. Since the error was not significant, it can be stated that the optimum conditions are 1:6 $(v / v)$ oil:alcohol ratio, $0.4(w / w)$ catalyst amount, $120 \mathrm{~min}$, and $60^{\circ} \mathrm{C}$.

\section{Fatty acid profile}

The composition of the algal biodiesel was analyzed using gas chromatography. Of the sample mixed with $10 \mathrm{ml}$ of methyl heptadecanoate solution, $250 \mathrm{mg}$ was injected into a flame ionization detector at $250^{\circ} \mathrm{C}$. The capillary column of length $30 \mathrm{~m}$ and internal diameter $0.32 \mathrm{~m}$ was coated with polyethylene glycol. The carrier gas was helium with a flow of 1 to $2 \mathrm{ml} / \mathrm{min}$ at a pressure of 30 to $100 \mathrm{kPa}$.

Figure 3 shows the composition of S. myriocystum biodiesel. It was found that monounsaturated fatty acids (MUFA) is $5.68 \mathrm{~g} / 100 \mathrm{~g}$, polyunsaturated fatty acids (PUFA) is $7.31 \mathrm{~g} / 100 \mathrm{~g}$, and transfat is $3.31 \mathrm{~g} / 100 \mathrm{~g}$. The sample is composed of saturated and unsaturated fatty acids with 10 to 36 carbon atoms. S. myriocystum biodiesel has $16.3 \mathrm{~g} / 100 \mathrm{~g}$ of unsaturated fatty acids and $82.1 \mathrm{~g} / 100 \mathrm{~g}$ 
(a)

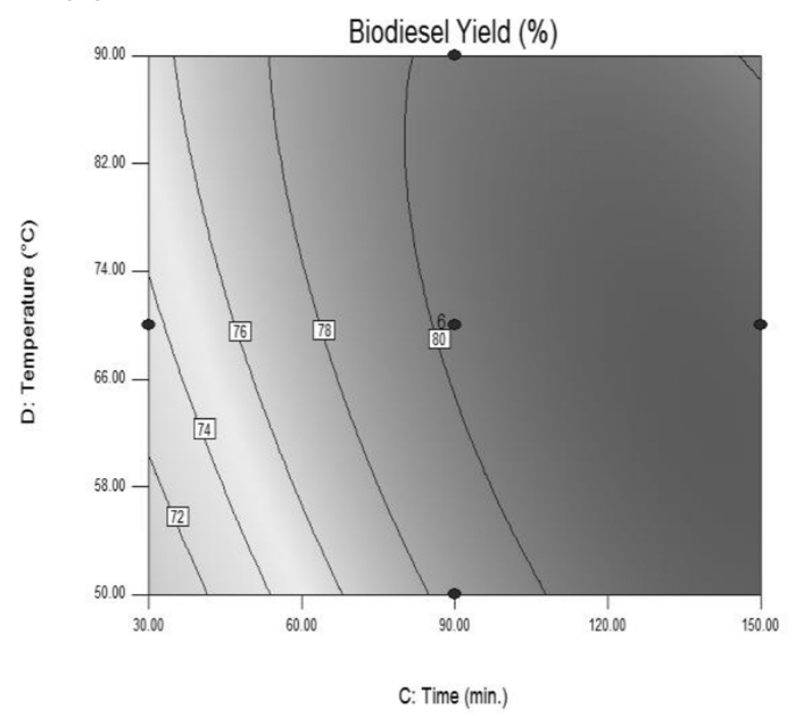

(c)

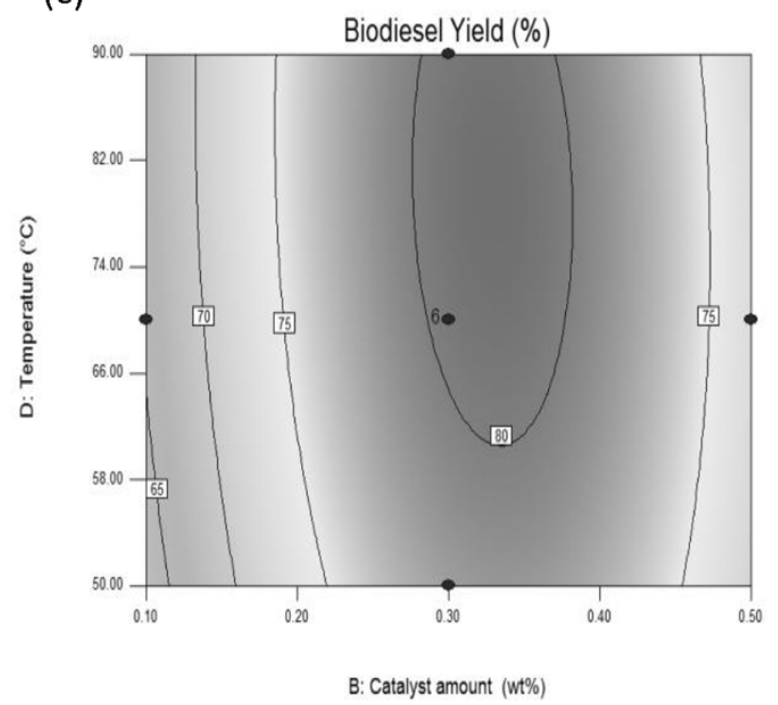

(b)

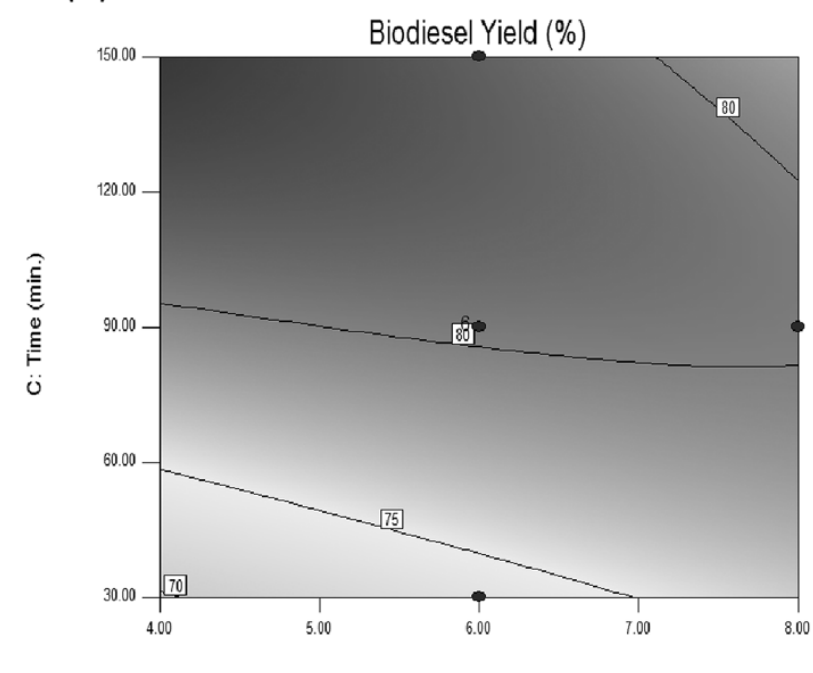

A: Oil:Alcohol ratio (V/v)

(d)

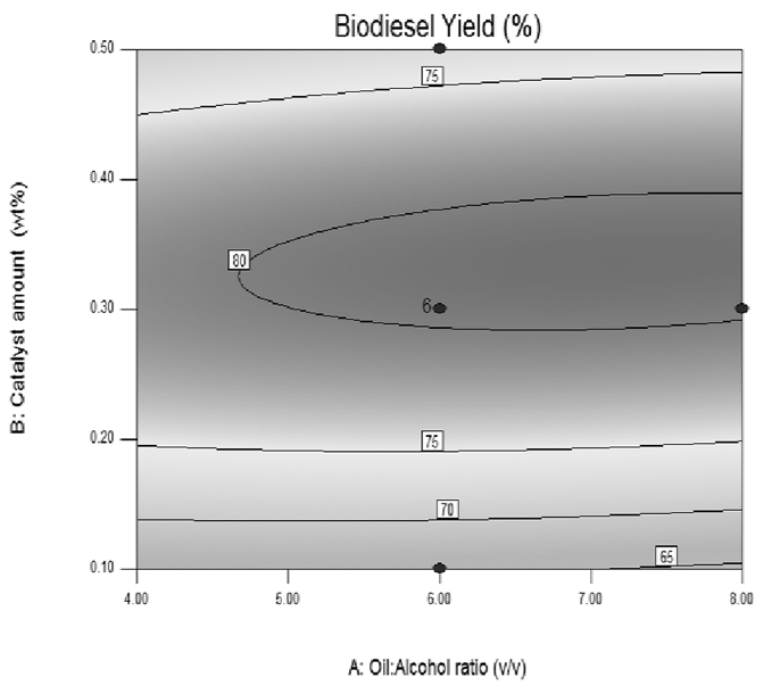

Figure 2 Contour plots for percentage yield (\%) of Sargassum myriocystum biodiesel. (a) Temperature (D) vs time (C). (b) Time (C) vs oil: alcohol ratio (A). (c) Temperature (D) vs catalyst amount (B). (d) Catalyst amount (B) vs oil:alcohol ratio (A).

of saturated fatty acids, indicating it to be a good prospective source for biodiesel [12].

\section{Storage properties}

A major disadvantage of widespread biodiesel commercialization is its low oxidation stability [24]. Conventional biodiesel is a hydrocarbon molecule having no oxygen integrated in its molecular structure, whereas algal biodiesel has fuel-bound oxygen atoms; hence, there is a lot of possibility of oxidation problems when it is exposed to air. The degree of unsaturation of biodiesel makes it susceptible to thermal and oxidative degradation leading to problems of injection in fuel systems [25]. Bouaid et al. studied the storage properties of high oleic sunflower oil, erucic Brassica carinata oil, and used frying oil. It was found that acid value, peroxide value, viscosity, and insoluble impurities decreased whereas iodine value increased with increase in storage time [26]. Das et al. studied the storage characteristics of karanja oil methyl ester over a period of 180 days and found that the addition of antioxidants like tert-butylated hydroxytoluene, tert-butylated hydroxyanisol, and propyl gallate increased the oxidative stability [27]. S. myriocystum biodiesel has a major advantage of having low amounts of unsaturated fatty acids. The unsaturation influences not only the engine performance but also the emission of pollutants into the environment. Emissions of pollutant gases like nitrogen oxides and carbon monoxides will be 


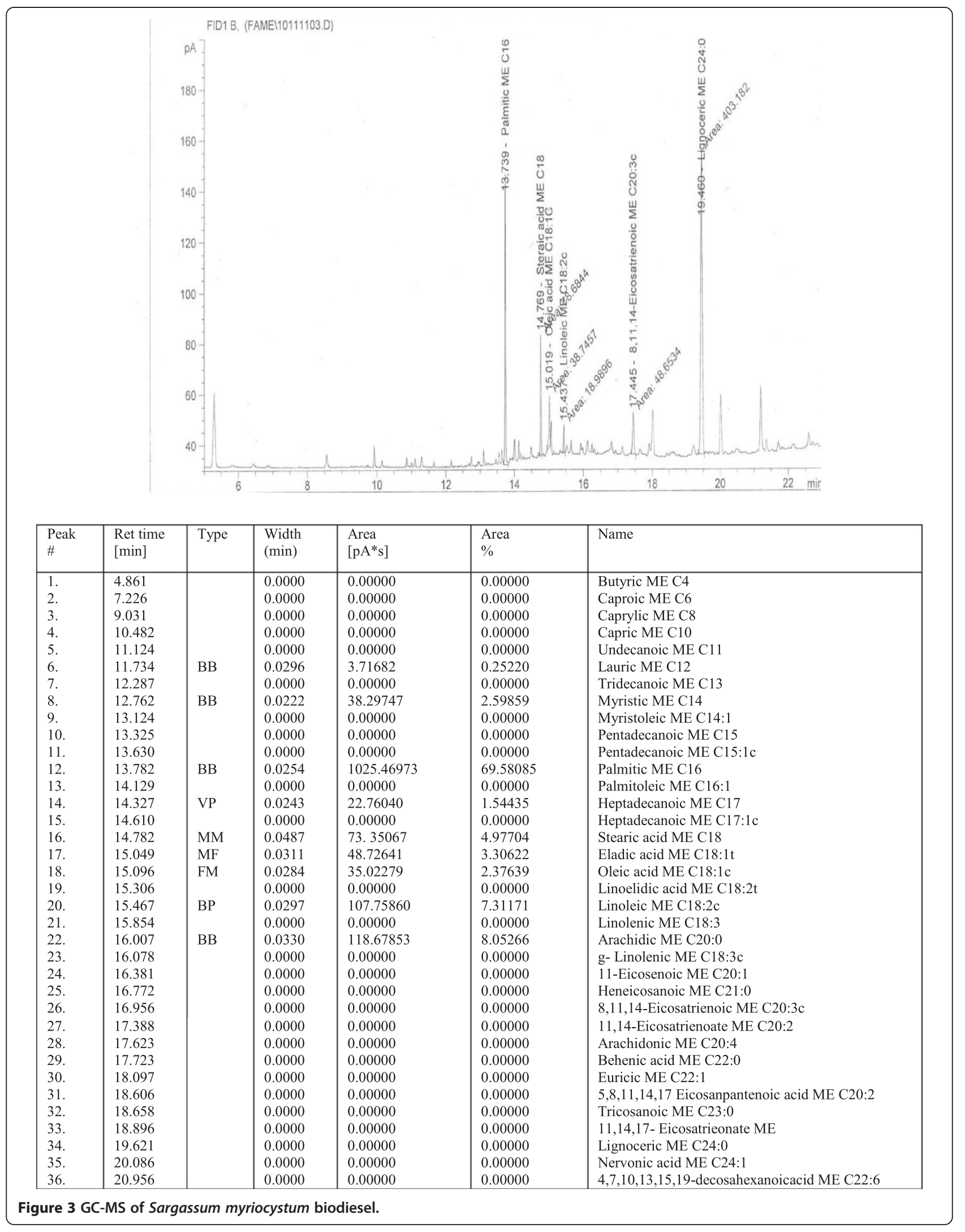




\begin{tabular}{lccccccc}
\multicolumn{8}{l}{ Table 4 Storage test results in dark and light conditions } \\
\hline $\begin{array}{l}\text { Sargassum myriocystum } \\
\text { biodiesel }\end{array}$ & $\mathbf{0}$ & $\mathbf{3 0}$ & $\mathbf{6 0}$ & $\mathbf{9 0}$ & $\mathbf{1 2 0}$ & $\mathbf{1 5 0}$ \\
\hline $\begin{array}{l}\text { In dark condition } \\
\quad \text { Kinematic viscosity (CSt) }\end{array}$ & 2.82 & 3.4 & 3.52 & 3.96 & 3.98 & 3.98 \\
$\quad$ Acid value (mg KOH/g) & 0.32 & 0.33 & 0.31 & 0.32 & 0.34 & 0.34 \\
In light condition & & & & & & \\
$\quad$ Kinematic viscosity (CSt) & 2.82 & 4.02 & 4.95 & 5.31 & 6.94 & 7.89 \\
$\quad$ Acid value (mg KOH/g) & 0.32 & 0.38 & 0.49 & 0.43 & 0.47 & 0.52 \\
\hline
\end{tabular}

high if the degree of unsaturation is high. Algal biodiesel has fuel-bound oxygen for combustion to be complete which ensures complete oxidation of pollutant gases.

Table 4 shows the storage tests done on biodiesel stored in dark and light conditions for a period of 150 days. The samples were periodically taken out at an interval of 30 days and were checked for both kinematic viscosity and acid value. Kinematic viscosity is an important property of all fuels. High viscosity results in negative impact on fuel injection system performance. The specified range of viscosity of the American Society of Testing Materials (ASTM D6751) is 2.5 to 6 . Kinematic viscosity was measured by an Ostwald viscometer. High viscosity leads to decreased atomization, fuel vaporization, and combustion. Samples stored in dark conditions showed only a marginal increase in kinematic viscosity for all samples which did not exceed the specified limits of ASTM D6751 as indicated by Table 4. For samples stored in light conditions, there was a sharp increase in viscosity values which exceeded the standard specifications. The viscosity rises during storage owing to the formation of polymers and to the hydrolytic cleavage of methyl esters into fatty acids [25]. Hence, the properties of the biodiesel samples stored in dark conditions are comparable to conventional diesel properties. Acid number indicates the corrosive nature of the fuel. The acid number for biodiesel should be lower than $0.50 \mathrm{mg} \mathrm{KOH} / \mathrm{g}$ according to ASTM D6751. Acid value was measured in the laboratory by mixing the sample with ethanol and heating in water bath and titrating it with potassium hydroxide using phenolphthalein as indicator. For samples stored in dark conditions, the acid values did not exceed the prescribed value after a period of 150 days and showed only a small difference from the initial value. The acid value is low for the samples stored in light conditions for a month but the value exceeds the prescribed limit after 150 days, indicating that the fuel had become very corrosive. This is in agreement with earlier studies [25,27]. There was sediment formation in the glass bottles after a period of 90 days, indicating that it cannot be stored and used as a fuel after 4 months. This could be due to the breakdown of molecular bonds and sample degradation. If the quality of biodiesel is not good and contains high degree of unsaturated fatty acids, it would tend to polymerize with the lubricating oil, forming sludge, and increasing engine wear [28]. Storage problems will be more for algal biodiesel than commercial diesel and shelf life is much reduced. The problems encountered in storing biodiesel for a long duration are mainly due to auto-oxidation, photo-oxidation, hydrolytic degradation, and oxidative degradation. This could be due to the fact that light can oxidize the oil. Degradation of the fuel has a profound influence on engine performance. The fuel was tested for calorific value before and after the test for both conditions of exposure to light and in the dark. The calorific value tested according to ASTM D6751 before the test was $41,499 \mathrm{~kJ} / \mathrm{kg}$. The calorific value of the sample kept in the dark after a period of 150 days is $38,700 \mathrm{~kJ} / \mathrm{kg}$, and that of the sample kept in light after a period of 150 days is $24,520 \mathrm{~kJ} / \mathrm{kg}$. The calorific value has drastically reduced because of molecular breakdown owing to degradation. A lower calorific value leads to more fuel consumption for the same amount of work done by a reference fuel. The engine will have high specific fuel consumption for the maintenance of a constant power output in maximum load conditions. Hence, it can be suggested that suitable additives can be added to the fuel to increase its shelf life and storage characteristics. Some additives for biodiesel storage found in literature are pyrimidinols [29], butylated hydroxytoluene, butylated hydroxyanisol, tert-butyl hydroquinone, propyl gallate, ethylenediaminetetraacetic acid, citric acid, phosphoric acid, and amino acids [30].

\section{Conclusions}

The brown seaweed S. myriocystum is a potential resource for biodiesel production. To make the process of making biodiesel cost effective, optimization of parameters was done using Design-Expert software version 8.0.7.1. RSM gave the optimum values of $120 \mathrm{~min}, 60^{\circ} \mathrm{C}$, 1:6 $(v / v)$ oil:alcohol ratio, and $0.4(w / w)$ catalyst amount. Maximum yield of biodiesel was achieved at the optimum conditions. The fuel was further investigated for its storage properties. It was found that the fuel deteriorated when exposed to air after a period of 4 months and started forming deposits with high increase in acid value. The fuel which was not exposed to air did not show a drastic change in kinematic viscosity and acid value but maintained a slow and progressive increase in the properties which did not exceed the limits prescribed by ASTM D6751. The calorific value of the fuel had drastically decreased to a lower value on exposure to light after a period of 150 days. It can be suggested that biodiesel prepared from S. myriocystum seaweed is best stored without any contact with air or suitable additives should be added to enhance the storage properties. In India, S. myriocystum 
seaweed is used in food and pharmaceutical industries. Since this paper substantiates its biofuel property which also meets ASTM D6751, it is an ideal crude for biorefineries.

\section{Competing interests}

The authors declare that they have no competing interests.

\section{Authors' contributions}

AR carried out the extraction, reaction, and optimization studies of the paper. NS performed the storage tests. MP identified the species and helped in the extraction of algal oil. All authors read and approved the final manuscript.

\section{Acknowledgements}

The authors wish to thank the Director of the National Institute of Ocean Technology, India, for the assistance provided. The authors also thank the editor and reviewers for their suggestions, thus improving the quality of the manuscript.

\section{Author details}

${ }^{1}$ Department of Chemical Engineering, Sathyabama University, Jeppiaar Nagar, Rajiv Gandhi Salai, Chennai TN 119, India. ²Department of Marine Biotechnology, National Institute of Ocean Technology, Velacherry-Tambaram Main Road, Chennai 100, India.

Received: 15 July 2014 Accepted: 7 October 2014

Published online: 31 October 2014

\section{References}

1. Shakeel A, Khan R, Mir Z, Hussain PS, Banerjee UL (2009) Prospects of biodiesel production from microalgae in India. Renew Sustain Energy Rev 13:2361-2372

2. Jeyabalan JPP, Johnson Marimuthu A (2012) Preliminary phytochemical analysis of Sargassum myriocystum J.Ag. and Turbinaria ornata (Turner) J.Ag from the southern coast of Tamil Nadu, India. Asian Pac J Trop Biomed 2:1-4

3. Fatih Demirbas M (2009) Biorefineries for biofuel upgrading: a critical review. Appl Energy 86:S151-S161

4. Mcneff CV, McNeff LC, Bingwen Y, Nowlan DT, Rasmussen M, Gyberg AE, Krohn BJ, Fedie RL, Hoye TR (2008) A continuous catalytic system for biodiesel production. Appl Catal Gen 343:39-48

5. Sharma R, Chisti Y, Banerjee UC (2001) Production, purification, characterization and applications of lipases. Biotechnol Adv 19:627-62

6. Roessler PG, Brown LM, Dunahay TG, Heacox DA, Jravis EE, Schneider JC (1994) Genetic engineering approaches for enhanced production of biodiesel fuel from microalgae. ACS Symp Ser 566:255-270

7. Sawayama $S$, Inoue $S$, Dote $Y$, Yokoyama SY (1995) CO $C_{2}$ fixation and oi production through microalga. Energy Convers Manag 36:729-731

8. Hu Q, Sommerfeld M, Jravis E, Ghirardi M, Posewitz M, Seibert M (2008) Microalgal triacylglycerols as feedstocks for biofuel production: perspectives and advances. Plant J 54:621-639

9. Schenk PM, Thomas Hall SR, Stephens E, Marx UC, Mussgnug JH, Posten C (2008) Second generation biofuels: high-efficiency microalgae for biodiesel production. Bioenerg Res 54:621-639

10. Maeda K, Owada M, Kimura N, Omata K, Kraube I (1995) $\mathrm{CO}_{2}$ fixation from the flue gas on coal-fired thermal power plant by microalgae. Energy Convers Manag 36:717-720

11. Patil V, Tran KQ, Giselrod HR (2008) Towards sustainable production of biofuels from microalgae. Int J Mol Sci 9:1188-1195

12. Williamson AM, Badr O (1998) Assessing the viability of using rape methyl ester (RME) as an alternative to mineral diesel fuel for powering road vehicles in the UK. Appl Energy 59:187-214

13. Sobha V, Surendran M, Vasudevan Nair T (1992) Heavy metal and biochemical studies of different groups of algae form Cape Comorin and Kovalam. Seaweed Res Util 15(1\&2):77-85

14. Badrinathan S, Suneeva SC, Shiju TM, Girish Kumar CP, Pragasam V (2011) Exploration of a novel hydroxyl radical scavenger from Sargassum myriocystum. J Pharm Res 5(10):1997-2005

15. Annam Renita A, Joshua Amarnath D (2011) Multifaceted applications of marine macro algae Sargassum myriocystum. J Pharm Res 4(11):3871-3872
16. Tressler DK (1951) Marine products of commerce. Reinhold, New York

17. Nadyaini WN, Omar W, Aishah N, Amin S (2011) Optimization of heterogeneous biodiesel production from waste cooking palm oil via response surface methodology. Biomass Bioenergy 35:1329-1338

18. Ferella F, Di Celso M, De Michelis I, Stanisci V, Veglio F (2010) Optimization of the transesterification reaction in biodiesel production. Fuel 89(1):36-42

19. Meher LC, Sagar V, Naik SN (2006) Technical aspects of biodiesel production by transesterifcation - a review. Renew Sustain Energy Rev 10:248-268

20. Khuri A, Cornell JA (1987) Response surfaces: design and analysis. Marcel Dekker, New York

21. Jang MG, Kim DK, Park SC, Lee JS, Kim SW (2012) Biodiesel production from crude canola oil by two-step enzymatic process. Renew Energy 42:99-104

22. Chen X, Wei D, Liu D (2008) Response surface optimization of biocatalytic biodiesel production with acid oil. Biochem Eng J 40:423-429

23. Zhang S, Zu YG, Fu YJ, Luo M, Zhang DY, Effreth T (2010) Rapid microwave-assisted transesterification of yellow horn oil to biodiesel using a heteropolyacid solid catalyst. Bioresour Technol 101:931-936

24. Karavalakis G, Hilari D, Givalou L, Karonis D, Stournas S (2011) Storage stability and ageing effect of biodiesel blends treated with different antioxidants. Energy 36:369-374

25. Mittelbach M, Gangl S (2001) Long storage stability of biodiesel made from rapeseed and used frying oil. JAOCS 78(6):573-577

26. Abderrahim B, Martinez M, Aracil J (2007) Long storage stability of biodiesel from vegetable and used frying oils. Fuel 86:2596-2602

27. Das LM, Bora DK, Pradhan S, Malaya K, Naik NSN (2009) Long-term storage stability of biodiesel produced from Karanja oil. Fuel 88:2315-2318

28. Leung DYC, Koo BCP, Guo Y (2006) Degradation of biodiesel under different storage conditions. Bioresour Technol 97:250-256

29. Wijtmans M, Pratt DA, Brinkhorst J, Serwa R, Valgimigli L, Pedulli GF, Porter NA (2004) Synthesis and reactivity of some 6-substituted-2,4-dimethyl-3-pyridinols, a novel class of chain-breaking antioxidants. J Org Chem 69:9215-9223

30. Knothe $\mathrm{G}$ (2007) Some aspects of biodiesel oxidative stability. Fuel Process Technol 88:669-677

doi:10.1186/s40643-014-0019-3

Cite this article as: Renita A et al:: Optimization of algal methyl esters using RSM and evaluation of biodiesel storage characteristics. Bioresources and Bioprocessing 2014 1:19.

\section{Submit your manuscript to a SpringerOpen ${ }^{\odot}$ journal and benefit from:}

- Convenient online submission

- Rigorous peer review

- Immediate publication on acceptance

- Open access: articles freely available online

- High visibility within the field

- Retaining the copyright to your article

Submit your next manuscript at springeropen.com 